\title{
Professional caregivers' perceptions on the prerequisites for and consequences of people with mild dementia using a digital photo diary
}

\author{
Christina Harrefors $^{1}$, Karin Axelsson ${ }^{2}$, Anders Lundquist ${ }^{3}$, Bengt Lundquist ${ }^{3}$, Stefan Sävenstedt ${ }^{2}$ \\ ${ }^{1}$ Department of Nursing, Umeå University, Umeå, Sweden \\ ${ }^{2}$ Department of Health Science, Luleå University of Technology, Luleå, Sweden \\ ${ }^{3}$ Department of Statistics, Umeå University, Umeå, Sweden \\ Email: christina.harrefors@nurs.umu.se
}

Received 21 January 2013; revised 25 February 2013; accepted 2 March 2013

\begin{abstract}
Research is currently ongoing to investigate the use of assistive technology by people with mild dementia to support independent living at home. The aim of this study was to describe professional caregivers' perceptions on the prerequisites for and consequences of people with mild dementia using a digital photo diary to facilitate their talks about daily events with their family members. A questionnaire was sent out to 582 participants (response rate $\mathbf{7 0 . 1 \%}$ ) to elucidate the professional caregivers' perceptions on the use of the digital photo diary. The questionnaire contained both quantitative and qualitative data and was analyzed with descriptive statistics, factor analysis, multivariate analysis of covariance and qualitative content analysis. This study reports the results related to prerequisites and consequences of using the photo diary. The results from the factor analysis revealed four factors: Trust, Vulnerability, Dependency/Independency and Control. The qualitative content analysis resulted in five categories: Immediate implementation after receiving a diagnose is required, Relatives' participation is a necessity, Strengthened self-esteem and meaningful everyday life, Increased alienation and a feeling of isolation and Assistive digital devices provide opportunities. The theme was interpreted as: Personalization and the preservation of dignity. The conclusion that can be drawn from this study is that the participants had an overall positive view of the usage of this specific digital photo diary for people suffering from dementia, but rigorous considerations needs before implementation of the device and regularly follow ups if dignity is to be maintained for people with dementia.
\end{abstract}

Keywords: Assistive Digital Devices; Dementia; Dignity; Factor Analysis; The Home; Qualitative
Content Analysis

\section{INTRODUCTION}

Forming values about different phenomena in a society is a dialectic process in that the values held are constantly changing. As humans, we are influenced by them and also influence them on an ongoing basis. Values are implicit in people's perceptions and the views they express about different phenomena cf. Sanders [1]. One can assume that this also applies to the way in which new Assistive Technology (AT) based on Information Technology (IT) is perceived and accepted as tools to promote the independence of people with dementia. Professional caregivers' opinions about people with dementia and the value to be obtained from the usage and the benefit of using a digital photo diary are of interest as professional caregivers are the ones who encounter and interact with the person with cognitive impairments on a continuous basis in the relatively early stages of dementia. In Sweden, nurses, physiotherapists, occupational therapists and social workers are those who are supposed to support people with physical, psychological and cognitive impairments with AT by providing them with suitable AT. Some research already exists describing the perspectives of health service personnel on the use of e-health solutions in the care of vulnerable elderly persons $[2,3]$. However, where assistive devices are concerned, there are few studies of the perceptions either of those working in close contact with dementia sufferers or of those who are afflicted themselves. Similarly, the matter of whether the use of specially designed digital photo diary is beneficial to people with cognitive impairments, or not has been given little attention.

\section{BACKGROUND}

Overall, basic values like freedom and independence are 
emphasized as being desirable in the modern Western culture. They are seen as fundamentals for people, along with and are closely related to the right to make one's own decisions. Autonomy is often interpreted in a liberal manner with a focus on independence, and it can be understood to be in a person's best interests to be able to make significant decisions regarding his or her life [4]. Randers and Mattiasson [5] discussed how the concept of having respect for people suffering from different diseases strengthens the autonomy of those afflicted, even if the autonomy varies, depending on the context. Autonomy and dignity appear to be mutually contingent and cannot, therefore, be separated if dignity is to be maintained. Autonomy is best maintained when a person makes her/his own decisions and remains independent. Losing independence is often equivalent to losing everything [6].

As a consequence of the cognitive impairments that a person with dementia suffers from, that person's autonomy is threatened and, furthermore, her/his dependence on others increases [7]. People in an early stage of dementia have described how they are constantly balancing their feelings of being valued and of worthlessness, as they struggle to remain someone of value [8]. In a review, Steeman and co-authors [9] stated that the necessity for better understanding of people in early stage of dementia is evident. The memory loss often results in a threatened sense of security, decrease in autonomy and a diminished feeling of being a meaningful member of the society.

Different "digital solutions" have the potential to meet some of the needs of people with cognitive impairments and can be used to improve the quality of life of the ageing person with mild dementia [10-12]. Benefits like increased independence and a greater feeling of wellbeing are described leading to an improved quality of life brought about by the use of assistive digital devices [2, $13,14]$.

AT is often used in the homes of people afflicted with dementia or other disorders/disabilities and illnesses in danger of affecting autonomy. That specific context has probably impacts on the values associated with the home and being cared for at home. The home is a unique place, a place to develop close and deep relationships. The home has an impact on our individual identity; it is a place we long for and dream about [15-17]. It contains a specific combination of material and symbolic attributes with strict boundaries between the official and the private. Different parts of the home, including possessions like pictures, furniture and fancy goods, all form parts of a person's life story. When people get older they spend more time in their homes and, because of that, the home becomes a particularly important place. In this situation, continuing to live in one's own home is a way to demon- strate to refuse to give in to the illness. Keeping one's home as one likes to have it gives a feeling of independence when suffering from decreased function and an increased level of disability [18,19]. As long as a person's memory is intact, the stories associated with each part of the home and the life of a person are integrated in the person, and this is also the case in the early stage of dementia, despite the life story as a whole becoming fragmented.

The provision and acceptability of support from AT to compensate for cognitive impairments is complex and there are many factors that can contribute to failure. Different disadvantages have been identified and there is a risk of imposing unethical intrusions and constraints, so these need to be taken into account. It seems that there are no right and wrong answers; instead, there is always a balance to be achieved, as has been reported previously in the literature $[2,20]$. With the development and implementation of AT, it is of great importance to elucidate ethical questions, regardless of the fact that they are inevitably sometimes thorny and this is especially the case for people with cognitive impairments, as they are often unable to give voice to their opinions [21-23]. This study will address this deficiency by tapping in to the evidence that carers are able to provide. After all, the professional caregivers have a crucial role to play in the adoption and usage of assistive digital devices for people with dementia and it is, therefore, important that their perceptions are described.

\section{CONTEXT}

The research and development of AT for people with dementia who still are living in their own homes, is a growing area of research. One example is a new assistive digital device, a digital photo diary, to support maintaining a life story for persons in the early stage of dementia [24]. In the main project, the mission was to create and validate a tool for capturing the events that comprised the everyday life of persons with mild dementia to make it available for later context-dependent retrieval. This digital photo diary contains three different components, a digital wearable camera, a home memory station and a smart phone, Table 1. The digital wearable camera hangs from the neck on a chain, cord or ribbon and takes photographs automatically that can be uploaded later onto a computer with a touch screen. A smart phone with a Global Positioning System (GPS) collects information about places visited. All information is strictly for personal use. Together with a relative or member of the health-care staff, it is possible for the person with dementia to use the uploaded photos and context-related information to review and discuss the events experienced during the day. 
Table 1. Descriptions of the three components of the digital photo diary used in the research project and in focus in this study.

\begin{tabular}{|c|c|c|}
\hline $\begin{array}{l}\text { Device } \\
\text { detailed }\end{array}$ & Application & Technical function \\
\hline $\begin{array}{c}\text { Digital } \\
\text { wearable } \\
\text { camera }\end{array}$ & $\begin{array}{l}\text { For daily use at home or } \\
\text { outdoors }\end{array}$ & $\begin{array}{c}\text { Taking photographs } \\
\text { automatically annotating } \\
\text { them with the time and } \\
\text { date }\end{array}$ \\
\hline $\begin{array}{l}\text { Home } \\
\text { memory } \\
\text { station }\end{array}$ & $\begin{array}{c}\text { For daily use with the assistance } \\
\text { of a relative or carer To look at } \\
\text { photos which show the people } \\
\text { that the person with dementia } \\
\text { has met during the day and } \\
\text { at which places }\end{array}$ & $\begin{array}{l}\text { Computer with touch } \\
\text { screen stores photographs } \\
\text { and sorts them according } \\
\text { to groups of people, } \\
\text { places and time }\end{array}$ \\
\hline $\begin{array}{l}\text { Smart } \\
\text { phone }\end{array}$ & $\begin{array}{l}\text { For daily use at home or } \\
\text { outdoors together with } \\
\text { the camera }\end{array}$ & $\begin{array}{l}\text { Detects position by Global } \\
\text { Positioning System (GPS) }\end{array}$ \\
\hline
\end{tabular}

\section{AIM}

The aim of this study was to describe professional caregivers' perceptions on the prerequisites for and consequences of people with mild dementia using a digital photo diary.

\section{METHOD}

\subsection{The Questionnaire}

The questionnaire was constructed by the authors of this study. The items in the questionnaire were based on three dimensions: security/control, freedom/autonomy and integrity/dignity. These dimensions were identified as important aspects of how healthy elderly people view the use of assistive technology services when they found themselves in need of care [20] and were also pointed out as being important ethical knowledge when implementing new technology for people with dementia in the documentation of the EU Biomed II project, Technology, Ethics and Dementia [25]. The questionnaire was based on a scenario. As the digital photo diary presented in this study was aimed to support elderly people with mild dementia, the scenario incorporated photographs presenting a newly retired woman with mild dementia (Hilda), showing a realistic picture of how the device was anticipated to work in her daily life. Her living condition including family situation with husband and children, previous profession as being a teacher and hobbies like photographing, engagement in outdoors activities and personal characteristics were described. The presentation of the scenario ends with a description of Hilda when she takes a walk in the neighbourhood using the wearable camera and being together with a friend where they sit in the front of the home memory station.

A series of questions divided in parts was presented in conjunction with this. Part I of the questionnaire consists of personal data relating to the respondent and his or her work-situation. Parts II - III relates to how the fictive person (Hilda) feels when carrying the camera and viewing photos by using the home memory station. In these two parts, a semantic differential technique with bipolar adjectives with a seven point linear scale $c f$. [26], covering the three dimensions was used. Part IV contains both negative and positive statements about the consequences of using this device and part $\mathrm{V}$ concerned statements about prerequisites for using the digital device. In both part IV and $\mathrm{V}$, a five point scale, ranging from strongly agree (1) to strongly disagree (5) was used. The last part VI of the questionnaire was an open ended question about important aspects of the device.

In the development process for formulating the questionnaire, a researcher engaged in semantics in the Swedish language reviewed the text. Six researchers with experiences of constructing questionnaires assessed the face validity of the questionnaire. Clarifying information was elicited about the appropriate wording of items. The items were discussed, thereafter revised or deleted based on the researchers' comments.

To confirm the construct validity the questionnaire was sent out to 70 registered nurses in specialist training programmes in the care of the elderly and district nursing (response rate $84 \%$ ). In the analysis of this pilot test, the Statistical Package for Social Science (SPSS, Inc., Chicago, IL, USA), version 18 for Windows was used. The Kaiser-Meyer-Olkin (KMO) indicated to go on with the principal component analysis (PCA) which measured the congruence between the items and the underlying structure cf. [27]. The results in the pilot test were interpreted as we had reached a construct validity of the questionnaire and a good reliability. In all steps of this validation process, comments from the participants were considered and included in the final version of the questionnaire, containing 79 items for further testing, Table 2.

\subsection{Participants}

In order to reach a study population that represented professional caregivers working with people with dementia in Sweden, a systematic selection was made by using an alphabetic registry over Swedish municipalities. From this registry, a key person in the care of the elderly was contacted in every third $(n=97)$ of a total of 290 municipalities. There was a good representation of different municipalities on relation to their size. Ten municipalities were identified where the management for the organisation of this care did not want to participate in the study, generally claiming lack of time as the primary reason, so ten new municipalities were recruited to replace them. The key person was provided with informa- 
Table 2. The description of the questionnaire.

\begin{tabular}{|c|c|c|}
\hline Parts & Content & $\begin{array}{l}\text { No of } \\
\text { items }\end{array}$ \\
\hline \multirow{9}{*}{ Part I } & Background questions & 8 \\
\hline & Age & \\
\hline & Gender & \\
\hline & Education & \\
\hline & Specialist training & \\
\hline & Present position & \\
\hline & Time spent working in present position & \\
\hline & Experience of working with people with dementia & \\
\hline & Use of computer during leisure time & \\
\hline Part II & $\begin{array}{l}\text { Bipolar adjectives about feelings of using } \\
\text { the wearable digital camera and the smart } \\
\text { phone, } 7 \text { point scale }\end{array}$ & 22 \\
\hline Part III & $\begin{array}{c}\text { Bipolar adjectives about feelings of using } \\
\text { the home memory station to view and } \\
\text { sort photos, } 7 \text { point scale }\end{array}$ & 22 \\
\hline Part IV & $\begin{array}{l}\text { Statements about the consequences of using } \\
\text { the digital device, } 5 \text { point scale from } \\
\text { strongly agree-strongly disagree }\end{array}$ & 21 \\
\hline Part V & $\begin{array}{l}\text { Statements concerning the prerequisites for } \\
\text { using the digital device, } 5 \text { point scale from } \\
\text { strongly agree-strongly disagree }\end{array}$ & 5 \\
\hline Part VI & $\begin{array}{l}\text { Open ended question about further important } \\
\text { aspects of using the assistive digital device }\end{array}$ & 1 \\
\hline Total & & 79 \\
\hline
\end{tabular}

*The same bipolar adjectives were used in Parts II and III.

tion about the study and the digital photo diary that was in focus in the study and asked to give their consent to the participation of their municipality in the study. The information also included the approximate time to complete the questionnaire, about 30 - 40 minutes. Thereafter, they were asked to identify six persons in their organization who fulfilled the inclusion criteria, which were: being care personnel with experience of working with people with dementia, and having a direct or indirect possibility to influence access to assistive digital devices. If, after receiving the questionnaire, the respondents had some concerns related to the questions, they were welcome to contact the researcher for further information and had been informed of this. The questionnaires were distributed as a printed form and were marked with the name of the municipality to make it possible to send a reminder to each municipality. After 1 month, an e-mail was sent out as a reminder to the key person in those municipalities that had not answered the questionnaire. In all, 408 out of the 582 participants approached completed the questionnaire, Table 3 . The data were col-
Table 3. Response rate and background information relevant to the participants.

\begin{tabular}{|c|c|c|c|}
\hline Background questions & $\begin{array}{l}\text { Total } \\
\text { (n) }\end{array}$ & $\begin{array}{l}\text { Percent } \\
(\%)\end{array}$ & $\begin{array}{l}\text { Male/Female } \\
\text { (n) }\end{array}$ \\
\hline $\begin{array}{l}\text { Number of questionnaires } \\
\text { distributed }\end{array}$ & 582 & 100 & \\
\hline $\begin{array}{l}\text { Answered questionnaires/response } \\
\text { rate }\end{array}$ & 408 & 70.1 & $17 / 383^{*}$ \\
\hline Dropouts & 174 & 29.9 & \\
\hline \multicolumn{4}{|l|}{ Present position } \\
\hline $\begin{array}{l}\text { Leader, project leader, care } \\
\text { developer }\end{array}$ & 67 & 16.4 & $6 / 61$ \\
\hline Registered nurse & 106 & 25.9 & $3 / 103$ \\
\hline Occupational therapist & 61 & 15.0 & $1 / 60$ \\
\hline Physiotherapist & 11 & 2.7 & $2 / 9$ \\
\hline Assistant nurse & 77 & 18.9 & $2 / 75$ \\
\hline Care administrator & 77 & 18.9 & $3 / 74$ \\
\hline Missing & 9 & 2.2 & \\
\hline \multicolumn{4}{|l|}{ Age } \\
\hline $20-29$ & 18 & 4.3 & $3 / 15$ \\
\hline $30-39$ & 63 & 15.7 & $3 / 60$ \\
\hline $40-49$ & 121 & 29.6 & $3 / 118$ \\
\hline $50-59$ & 143 & 35.0 & $6 / 137$ \\
\hline $60-69$ & 55 & 13.4 & $2 / 53$ \\
\hline Missing & 8 & 2.0 & \\
\hline
\end{tabular}

lected from March until May 2010.

\subsection{Analysis}

This study explored the respondents' responses to the questionnaire from parts I, IV, V and VI, while parts I, II and III are published elsewhere [28]. The data was analyzed with descriptive statistics, multivariate statistics and qualitative content analysis.

\subsubsection{Statistics}

To characterize the participants and the responses to the items in some parts of the questionnaire, we used descriptive statistics. A Factor Analysis (FA) was performed in order to obtain a description of the underlying structure of the 21 variables concerning the perceived consequences that the use of the digital photo diary had on Hilda's way of life in the written presentation. The use of a factor analysis makes it possible to describe the variance of observed manifest variables in terms of a lower number of unobserved variables. This method is 
commonly used when there is a need to reduce a large numbers of observed variables to form a manageable and comprehensive summary. The same procedure used to analyze the data in the pilot study was used in the original study. The KMO test received from the factor analysis for this part in the questionnaire, concerning consequences, was high, 0.827 , which implied that the matrix was well suited for the factor analysis. To explore the dimensionality of the scale, we began with a PCA and determined the factor loadings. We then used the varimax method with Kaiser normalization to rotate the initial factor and determine the communalities. Reliability as the internal consistency of the responses was measured by Cronbach's alpha. We scrutinized our factor loadings, interpreted and labelled them based on the included items. A multivariate analysis of the covariance, (MANCOVA), was used to investigate the main effects and the interactions between the categorical variables on multiple dependent interval variables [27]. In part V, which concerns the prerequisites, the answers were analysed with descriptive statistics.

\subsubsection{Qualitative Analysis}

Qualitative data taking the form of written responses to the open-ended question about the respondent's concerns of using the digital photo diary was analysed with qualitative content analysis cf. Elo and Kyngäs [29] and Granheim and Lundman [30]. More than a third of the participants gave written comments and advices in this part of the questionnaire (167 respondents, $40 \%$ ). These comments contained general aspects related to using the digital photo diary and some aspects concerned wearing the camera. In performing the analysis, the written responses in the questionnaire were first transcribed wordfor-word to a separate document and thereafter read through by all of the authors of this manuscript to obtain an initial understanding of the content. The text was divided into meaning units in correspondence with the aim of the project. Thereafter, the meaning units were condensed into a description of the content, coded and sorted into two groups, one for prerequisite and one for consequences. In all 14 sub categories of content was identi- fied that were further abstracted and resulted into two categories describing prerequisites and three describing consequences. Finally all content was integrated and abstracted into a theme describing how digital photo diary could be meaningful for people with dementia.

\subsection{Ethics}

Participation in the study was voluntary and the questionnaires were answered anonymously. The study was approved by the Regional Ethical Review Board in Umeå, Sweden (Dnr 09-132M).

\section{RESULTS}

The results report prerequisites and thereafter imaginable consequences for using the digital photo diary.

\subsection{Prerequisites}

The analysis of the quantitative data about prerequisites showed that the respondents agreed that having experience of using and being accustomed to a computer and a smart phone was necessary for the digital photo diary to be meaningful both for the person suffering from dementia and the relative, Table 4. An overwhelmingly large part of the respondents answered that the device should be introduced in early stage of dementia, as soon as possible after a person was diagnosed as having dementia.

The qualitative content analysis of prerequisites resulted in two categories of content that were named; Immediate implementation after receiving a diagnosis; and Relatives' participation is a necessity.

\subsubsection{Immediate Implementation after Receiving a Diagnosis}

Being accustomed to and having experience of using digital technology were emphasized as prerequisites of being able to use the digital photo diary under consideration properly.

Many of the participants expressed a view that increased cognitive impairment would be a hindrance to using the device and, in particular, would make learning

Table 4. Prerequisites if the digital photo diary would be meaningful for the person with mild dementia. Agree range 1 - 2, neutral 3 and disagree range 4 - 5 .

\begin{tabular}{|c|c|c|c|c|}
\hline Variable & Agree & Mean & Median & Std. Deviation \\
\hline Hilda being used to using a computer & $69.1 \%$ & 2.10 & 2.00 & 1.244 \\
\hline Hilda being used to using a smart phone & $62.3 \%$ & 2.33 & 2.00 & 1.330 \\
\hline Relatives being used to using a smart phone & $69.2 \%$ & 2.07 & 2.00 & 1.283 \\
\hline $\begin{array}{l}\text { The digital photo diary should be introduced shortly } \\
\text { after the diagnosis has been made }\end{array}$ & $90.0 \%$ & 1.39 & 1.00 & 0.780 \\
\hline
\end{tabular}


how to use it more difficult. Therefore an early introduction was emphasized due to the progressive nature of dementia. In the beginning, when the disease is in its early stage, it is possible for the person with the diagnosis of dementia to learn how to handle the device, but this might be difficult in a later stage, "One should get [the digital photo] diary soon after the diagnosis is made so that one can learn how to use it and it becomes part of the daily routine ... while one is still living in one's private home".

Another prerequisite mentioned was the need to make assessments of individual needs for the person with dementia. The respondents emphasised that, for the device to become meaningful for the user, it was necessary to know the users' life history and interests in terms of digital technology usage before having the diagnosis. It was also stated that there was a need to know the person's ability to learn, what insights the person has about their disease, and how the person understands the situation, "Whether [the digital photo diary] will be experienced as meaningful or not is dependent on each person since the dementia-related problems are experienced in different ways by different people".

It was stated that people with previous experience of digital technology, such as using a smart phone and having an interest in taking photos will probably have advantages over people without any experience of this kind at all. It was also stated that knowledge of how to use assistive digital devices in general makes it easier to learn and handle new devices, because one feels comfortable with them. A lack of computer knowledge requires a high learning potential and a significant level of interest for the device to be meaningful. The participants also stressed that relatives' previous knowledge of digital technology might also be of importance as pervious usage will have demonstrated the advantage and assistance the use of such devices can bring, "It [the device considered in this investigation] will be meaningful for a person with existing computer knowledge, experience of using smart phones, who is also interested in photography".

\subsubsection{Relatives' Participation Is a Necessity}

This category focuses on the prerequisite that the relatives' engagement and involvement is a necessity if the digital photo diary is to be meaningful for the user. Some of the respondents mentioned that the relatives' attitudes towards the device could have an effect on its meaningfulness for the user.

Relatives' motivation, curiosity and interest were stressed as being necessities for the digital photo diary to be meaningful for the person with dementia, "In order for it to work well it is important to ensure the curiosity and engagement of the relatives ... they are an important part of everyday life that will be captured in the photos". Some also mentioned that spending time with locking at and sorting photos when using the computer has an effect upon how the device is perceived to be meaningful for the user. Without engaged relatives, there is a risk that the digital photo diary only remains a technical tool, without having any relevance to the user.

At the same time as the relatives were mentioned as a great resource for the usage of the device, it was also stated that, being relative to a person with dementia is perceived as a burden. Therefore the provision of information about the device and providing the time for training with it and supporting it is of great importance. In order for the device to be useful for the person with dementia several prerequisites must be fulfilled, however, "If the relatives really follow up and communicate about what the person with dementia has experienced during the day, it can be very stimulating".

\subsection{Consequences}

The unrotated PCA resulted in a four-factor solution with an eigenvalue $>1$. The four factors emerged from the explorative factor analysis, (EFA), were interpreted and labelled as: Trust, Vulnerability, Dependency/Independency and Control. Fifty seven percent of the variance could be explained by these factors, Table 5. Trust comprises consequences like, security, safety outdoors, possibility to stay at home, freedom, safety at home, wellbeing, interaction with others, health, and strengthen memory. This factor accounted for $33.1 \%$ of the total variance which indicates that sense of trust can be seen as an important aspect by using the device. The scale ranged from 1 - 5 and the mean value of the estimations of the items in the factor Trust was $2.09-2.54$, is also an indication that Trust can be seen as a positive tendency of the consequence by using the digital photo diary. Vulnerability, are mirroring consequences like insecurity, alienation, lack of safety, isolation at home, poor health, intrusion in the private sphere and stigmatization. The mean value of the estimations of the items in this factor was 3.15 - 4.22. High value mean low risk for vulnerability due to the questions was formed as a negative statement. Put it in another way, the respondents seamed to disagree that there is a risk for vulnerability by using the device. The results from Reliability testing indicated that factor 1 and 2 were sufficiently homogenous in terms of their Cronbach's alpha coefficients $0.88,0.80$ respectively.

Dependency/Independency included the items independence of nursing staff/relatives and dependence on nursing staff/relatives. The mean value ranged 2.77 3.59. For estimating the mean value the scale was inverted for the 2 negative statements in this factor. Actu- 
Table 5. Results of the FA, revealing what consequences the digital photo diary is likely to have for the user.

\begin{tabular}{|c|c|c|c|c|}
\hline & Factor 1 & Factor 2 & Factor 3 & Factor 4 \\
\hline \multicolumn{5}{|l|}{ Trust } \\
\hline Security & 0.799 & & & \\
\hline Safety outdoors & 0.792 & & & \\
\hline Possibility to stay at home & 0.753 & & & \\
\hline Freedom & 0.683 & & & \\
\hline Safety at home & 0.678 & & & \\
\hline Well-being & 0.532 & & & \\
\hline Interaction with others & 0.526 & & & \\
\hline Health & 0.481 & & & \\
\hline Strengthen memory & 0.445 & & & \\
\hline \multicolumn{5}{|l|}{ Vulnerability } \\
\hline Insecurity & & 0.747 & & \\
\hline Alienation & & 0.727 & & \\
\hline Lack of safety & & 0.719 & & \\
\hline Isolation at home & & 0.653 & & \\
\hline Poor health & & 0.643 & & \\
\hline Intrusion in the private sphere & & 0.604 & & \\
\hline Stigmatization & & 0.519 & & \\
\hline \multicolumn{5}{|l|}{ Dependency/Independency } \\
\hline Independent of relatives & & & 0.782 & \\
\hline Independent of nursing staff & & & -0.776 & \\
\hline Dependent on nursing staff & & & 0.753 & \\
\hline Dependent on relatives & & & -0.677 & \\
\hline \multicolumn{5}{|l|}{ Control } \\
\hline Control over one's life & & & & 0.763 \\
\hline Cronbach's alpha & 0.889 & 0.809 & -1.059 & \\
\hline Eigenvalue & 6.961 & 2.126 & 1.930 & 1.085 \\
\hline Percentage variance & 33.148 & 10.126 & 9.191 & 5.166 \\
\hline
\end{tabular}

ally there are only two statements in this factor, but asked from an opposite view there were four items included. The Cronbach's alpha coefficient for this factor was -1.059 . The negative covariance is a consequence that there are questions about dependence and independence, asked in opposite ways. If the answers for depend- ence are high the answers for independence are low. Out of the mean value it can be seen that the respondents had a neutral view regarding the factor Dependency/Independency as a conesquence of using the digital photo diary for people with mild dementia. Only one item loaded into the last factor, Control. As the factor loading was relatively strong (loading 0.763 ), we decided to retain it as one factor. That factor indicates that it could have been more questions in the questionnaire concerning the factor Control. The fourth factor was not tested for Cronbach's alpha. Mean value was 2.20, which indicated a tendency to agree that the device can support being in control.

A MANCOVA was performed using age as a covariate to investigate whether there were any differences in the factor scores between different "present position" and/or "gender". The interaction between the "present position", meaning the viewpoint expressed, and "gender" was not significant at the 5\%-level and, thus, was excluded from the model. Both "gender" and "present position" were significant main effects in the multivariate tests $(\mathrm{p} \leq 0.01)$. The follow-up univariate analyses indicated that "gender" had a significant impact on the factor Control, i.e., men has a significantly higher average score than women for that factor. The "present position" had an impact on the factor Dependency/Independency, as shown in Figure 1, where it turned out that assistant nurses had a higher average score compared to those engaged in other positions. The differences between assistant nurses and registered nurses and between assistant nurses and occupational/physiotherapists were significant ( $p<0.001$ and $p=0.004$, respectively), and the difference between assistant nurses and leaders were close to significant $(p=0.051)$. This can be interpreted as a tendency that assistant nurses seemed to agree stronger with the items about dependence than those employed in other positions.

The qualitative analysis of the consequences resulted in three categories of content named; Strengthened selfesteem and meaningful everyday life; Increased alienation and a feeling of isolation; and Assistive digital devices provide opportunities.

\subsubsection{Strengthened Self-Esteem and Meaningful Everyday Life}

In the comments the informants had concerns about how the use of the digital photo diary under consideration can support the memory and the life story of a person using the device, and whether it would enable that person to maintain his/her social competence and autonomy. Possible consequences of using the device would be that users experience themselves to be healthy and to have fewer problems with their cognitive impairments.

From the comments made by the informants, it ap- 


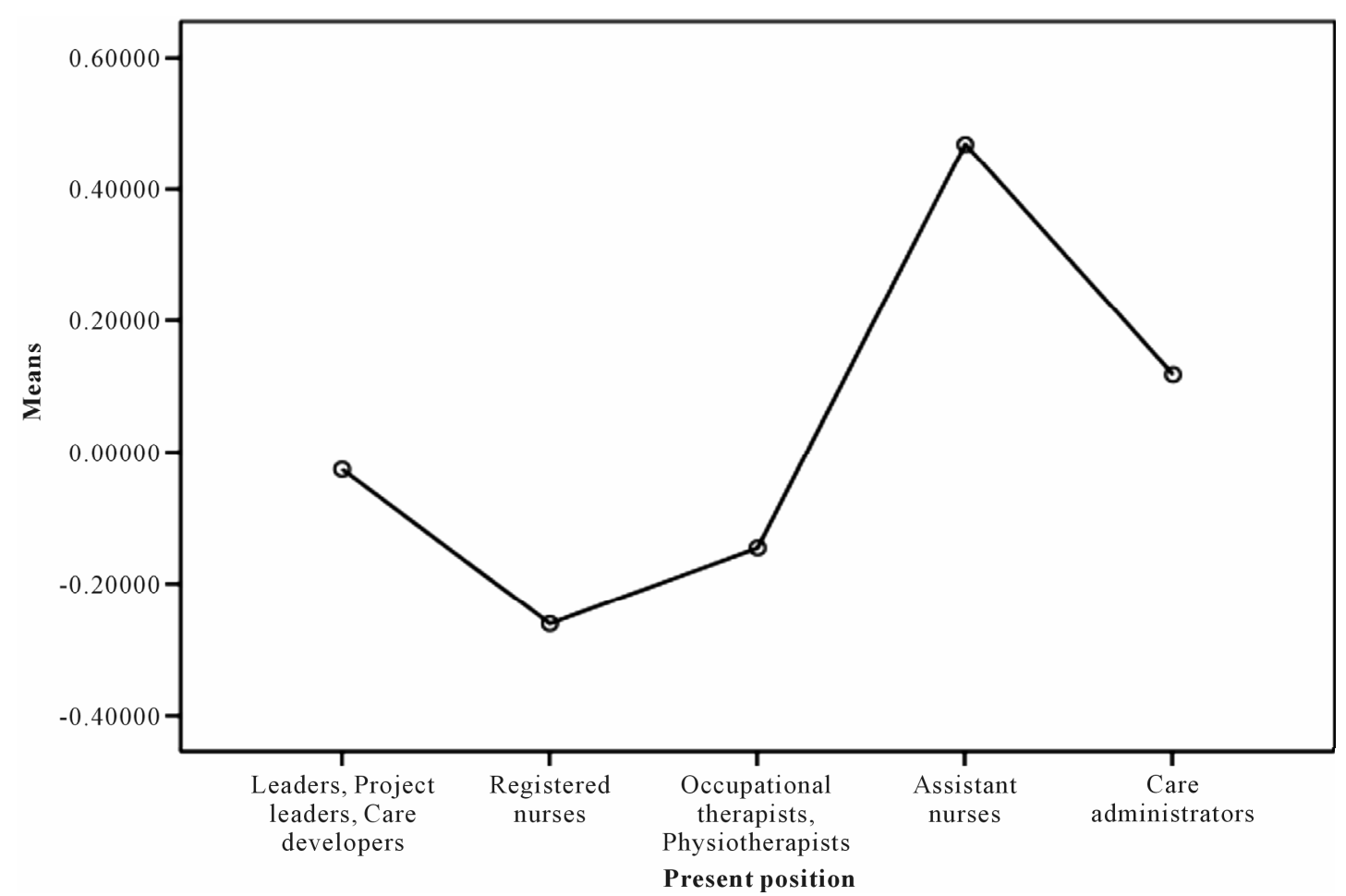

Figure 1. Means for the scores illustrate the impact of present position on the factor Dependency/Independency.

pears that the act of talking about what can be seen in the photos, which people are shown in them and what has happened during the day are good for a person with early stage of dementia. The memory training was perceived to be of importance to retain the existing state of health and to impede the dementia, "The possibility of bridging the life story of the past with the present ... can be communicated with others and that provides a feeling of being part of life". By training the memory, the device preserves the person's state of health, and promotes freedom and autonomy.

Several comments were made that stressed how the quality of life would be improved for the person with dementia when using the digital photo diary in a familiar environment. It was perceived that the use of the device could strengthen the relationship with relatives through the act of looking at and communicating on the photos, "The device supports the relationship between the person with dementia and their relatives. They have something to talk about. Relatives living far away will have an opportunity to share everyday life with the user".

The availability of information in pictorial form enables the elderly person with dementia to share their experiences with their friends and family, thereby providing pleasure from using the digital photo diary as well as a sense of security. It was perceived that, in order for the device to be meaningful for the person with dementia, the support of relatives would be necessary. It is "also good for the relatives and close friends to see how the person with dementia spends the day and what choices she makes on her own now with the disease present".

\subsubsection{Increased Alienation and a Feeling of Isolation}

This category comprises important aspects of what perceived consequences the usage of the digital photo diary could have for a person suffering from dementia, especially negative consequences. Many of the comments made by the respondents dealt with the possible feelings the person with dementia might have when wearing the camera outdoors, and also with possible reactions from the people she meets.

There were concerns about whether the person with dementia would be able to answer questions if somebody demanded an explanation of the device. Being pushed into situations such as these when suffering from cognitive impairments could be stressful, and lead to an increase in feeling that one was being controlled when carrying the camera, and adding to a sense of frustration and reducing self-confidence, "I believe that some people might be reluctant to wear the camera since some probably experience it as a sign saying 'I have dementia...' and it could be uncomfortable having to explain why one is wearing a camera around one's neck when one meets people in the street who don't know about the illness".

Other perceived negative consequences noted are experiencing a sense of isolation, and feelings that an intrusion is being made on one's integrity and of being controlled. Some participants also stated that the digital 
photo diary might be difficult to use. Furthermore, if the user does not understand the techniques, then the attempt to use the technology could result in increased confusion and frustration. For a person with a cognitive impairment, all of these feelings are mentioned as aspects that might reduce the person's self-confidence and increase their feelings of insecurity. As one respondent said, "The risk of not being able to handle [the digital photo diary] may create frustration, worries and confusion".

Many of the comments concerned what the use of such an assistive digital device might lead to: a surveillance society, with "Big Brother" watching. Some mentioned a horrible futuristic society where the technology could be valued as being more important than the human interaction. It was also stated that using the device might lead to a false sense of security. Depending on who is going to look at the photos, the device might be felt to be intrusive: "Some thought should perhaps also be given to who is going to go through the material collected in order not to violate the integrity [of the person with dementia carrying the camera]."

\subsubsection{Assistive Digital Devices Provide Opportunities}

There was a general sense of anticipation among many of the participants that assistive digital devices heralded a bright future since that the development of $\mathrm{AT}$ is so rapid that it taking place at lightning speed. Comments on the potential of the device presented in this investigation ranged from how the device could, and should be developed further, to suggestions of other areas in which it could be used. In general, the statements were very positive. There were also comments about the importance of the digital photo diary being both safe and reliable, saying that both the person with dementia and the relatives must have confidence in the technology to avoid uncertainty and ensure the safety of the person with dementia, "It is fantastic that the device records the content of the day ... it requires [relevant] previous knowledge and computer knowledge ... it is good because it provides an opportunity for persons with dementia to contribute to social situations". There was a sense that the type of the digital photo diary under consideration will become very useful in the future when more elderly people have had a general experience of working with computers and of using digital technology. Some of the comments stated that the device could be useful in similar areas, not only for people with dementia.

The statements made also included recommendations for simplicity and the ease of handling the equipment. In addition, concerns were expressed about the camera and of needing to be conscious of wearing it, as exemplified by the quotation, "If Hilda takes off the camera or puts down the smart phone when she is away from home... how can she be made aware of it? An alarm?"

\subsection{Integrated Results}

\section{Personalization and Preservation of Dignity}

An over-arching theme was formed based on an integration of all results describing how digital photo diary could be meaningful for people with dementia. A central and recurring concern was that of the consequences the use of the digital photo diary could have for the person with dementia if the device did not meet the personal needs in the context she/he was living in. Personalization seems to be a prerequisite for the dignified use of the device. The preservation of dignity seems to be mainly connected with the discussions held when reviewing the photos on the computer, so the relatives' contribution is vital for ensuring the dignity of the individuals concerned. Furthermore, it is emphasized that the relatives' contribution is a critical part of ensuring the dignified use of the material gathered along with the possibility of supporting the life-story of the person with dementia.

\section{DISCUSSION}

The aim of this study was to describe professional caregivers' perceptions on the prerequisites for and consequences of people with mild dementia using a digital photo diary. Important aspects of the prerequisites were the early introduction of the device while the person with dementia still is able to understand, and that the person concerned has the support of relatives. Strengthened self-esteem and a meaningful everyday life was a valuable consequence from the comments. From the factor analysis, trust was the dominating factor and also evaluated as a positive consequence. As for possible negative consequence, those mentioned were an increased alienation and a feeling of isolation for people with dementia. Vulnerability was defined as a factor from the factor analysis, but the participants did not agree there was a risk for vulnerability by using the device for person with dementia. The results from quantitative data about perceptions supported the results from the qualitative data. The main theme from the quantitative and the qualitative analysis was interpreted as "Personalization and preservation of dignity".

The ability to respect the dignity of the people afflicted with dementia was a prerequisite for using the device, and was, therefore, deemed to be an important value. When Edlund [31] describes the concept of dignity, she includes three dimensions: spiritual, bodily dimension and psychological. The central core in this trinity connects these dimensions, the absolute dignity, where holiness of the human is prominent. This value is always present in humans and can never suffer insult; and it is surrounded by freedom, responsibility, duty and a desire to serve, all of which are given in the human being from the beginning. Related to the concept of ab- 
solute dignity is that of relative dignity, which can be seen as concerns of the internal experience of pride, respect, power and position, and the external values related to the bodily dimension of respect, authority and control. Nordenfelt [32] discusses the concept of dignity in a similar way, as an intrinsic absolute value of being a human. The concept of dignity consists even in dimensions, which can be influenced depending on the situation.

From the participant's perspective, personalisation of the digital photo diary was seen as a prerequisite for being able to maintain dignity. Dignity was also connected to the possibility of talking with relatives about daily events and, thereby being able to maintain their personal life story. This corresponds to Nordenfeldt's [32] concept of dignity as a merit and as a moral status, and to Edlund's [31] concept of the relative dignity. In addition, the ability to be able to continue living at home in a familiar environment with the support of the digital photo diary can be assumed to strengthen feelings of both security and trust, and consequently also the dignity of the person with dementia. Dignity is closely associated with being able to manage daily activities and the importance of being an active person was also emphasised in a study where people with head injuries described what dignity meant for them [33].

The possibility the digital photo diary provides of maintaining the life story of the participants, and their perceptions of who they were in their early lives and who they are in the present time, could provide a way to maintain and enhance their dignity. With support from relatives and the assistance of the photos taken by the camera, persons with mild dementia could discuss the events of the day, which was emphasised as offering a way to strengthen their independence and maintain their identity cf. Edlund [31] and Nordenfelt [32]. Social interaction is the base for developing one's sense of self and self-consciousness, and the social context can be interpreted as something that offers the opportunity to shape one's identity and awareness [34,35]. For people suffering from dementia, their perceptions of their own life, telling their life story, was interpreted as a vital aspect of their sense of identity [36,37]. When Kitwood [38] discussed how to achieve the goal of maintaining personhood and of assisting people with dementia to attain a sense of well-being, he points out the importance of interactions with others in this process. Interactions should be formed from a mode where actions and utterances are assumed to be meaningful, and one should attempt to understand people with dementia from their own context, both from their own life story examined from a historical context or in the present. The results from this study stress that the talks between the person with dementia and her/his relatives when discussing the photos taken and the daily events offer an important opportunity for building a meaningful interaction. This interaction has the potential to provide a feeling of well-being for the person with dementia and to help them to maintain their personhood.

Trust was measured as the factor in the factor analysis that most of the participants agree with the statements compared to the statements in the other factors, and can be seen as an important consequence in the care of elderly, characterized by dignity. It seams reasonable to assume that, especially for people with cognitive shortcomings, strengthening of a sense of trust can enhance their sense of well-being. Flanagan [39] describes trust as a multidimensional construct, fundamentally relational and an ongoing process throughout life, built on the sense of security developed in early nurturing relationships. It is reasonable to assume that the assumption that the use of the device by people with dementia can support a sense of trust is based on the interactional aspects of the usage of the digital photo diary.

Respecting people's autonomy is a core element in quality care [4] and is closely connected to the concept of integrity $[5,40]$. Autonomy is often related to independence and as it is well-known that the disease of dementia is characterized by loss of memory, function and behaviour, capacities that make up and define an autonomous person is reduced. Regardless of this there is a need for people suffering from dementia to retain a sense of being in control. Different studies have described how the use of technology is being identified as a means to enhance independent living, and improve the safety and the independency for people with dementia $[41,42]$. The participants in the study presented here, when considering the use of a digital photo diary for people with dementia, it seams as they had a neutral view to the device contributing dependence and independence.

Notable findings from the quantitative data were the impact that gender and the present position was revealed to have on certain factors. It emerged that men rated item in the factor Control higher than women did, which can be interpreted as that they more than woman disagree that control is of importance. As there were few men, (n $=17$ ) participating in the study, it is difficult to draw firm conclusions, but nevertheless, it is indicative of an interesting tendency. For the factor Dependency/Independency, it was a tendency that assistant nurses seamed to agree stronger with the items about dependence than those employed in other positions. It can be assumed that assistant nurses work more closely with people with dementia than the other groups of participants. The closeness of the assistant nurses to those with dementia and the amount of time they spend with them might provide assistant nurses with a good understanding of demented person's everyday life, and consequently hold a different 
view on the meaning of dependency to those with dementia and it being valued as a matter of prime importance to them. However, to make additional interpretations more studies have to be done that confirm this.

The participants in the study presented here perceived the digital photo diary under consideration as having great potential in the future. Similar views were expressed by informal carers in another investigation, where network technology was considered to be something that would be more useful for the next generation [11]. In the same study, the necessity of having more information was also pointed out, as was a need for training and for ongoing support to enable those for whom the technology was intended to use it; again, this agrees with the statements made by the participants in the current research.

\section{METHODOLOGICAL CONSIDERATIONS}

The research presented here focused on how professional caregivers perceive the prerequisites for and consequences of people with mild dementia using a digital photo diary. The function of the digital photo diary was presented through the use of a scenario, and none of the participants had seen the device in reality. This must be taken into consideration when discussing the results. However, we think that the structured way of using a scenario about a person with dementia (Hilda) and providing a detailed description of the digital photo diary when Hilda was using it was a guarantee for the uniformity of the responses. By using hypothetical scenarios, it is possible to enhance knowledge about the use of digital photo diary as clarified by Fung et al. [43]. On the basis of the comments made in the open-ended question, it is obvious that the way of using the digital photo diary has been understood by the participants. However, it is also likely that the way the participant responded was influenced by the scenario presented, and that the responses might have been different if the age, gender and the context of the person presented in the scenario had been different.

Attention ought to be paid to aspects like trustworthiness in qualitative studies, and the study under consideration here was supported by using rigour in all parts of the process comprising the analysis, where all steps were checked by all the authors $c f$. [44]. The researchers collaborated until a general agreement was reached in all steps of the study. In addition, the labelling of factors from the analysis of the factor analysis always relies upon interpretation, with the consequence that there is a risk of misinterpretation. However, this aspect has been discussed thoroughly between the authors, which minimises the potential risk.

\section{CONCLUSION}

The results indicate that the participants had an overall positive view of the usage of this specific digital photo diary for people suffering from dementia and that there were some differences in the views expressed by different professional groups among the professional caregivers. A major conclusion that can be drawn from the results of this study is that different aspects contributing to a sense of dignity are core values when perceiving the use of this digital photo diary by people with dementia. Dignity was related to the perception of prerequisites as the importance of personalising the use of the device was evident, and the need to ensure that there was an early introduction of assistive digital devices of this kind after receiving a diagnosis was apparent, to ensure that the devices were introduced while people with dementia are still able to handle them. This was also associated with the balance between the perceived positive and negative consequences of using the device. The perceptions and imbedded values revealed in this study reflect the perceived use of a specific digital photo diary. It is likely that this also have a bearing on other assistive digital devices developed to support people with dementia, which has to be confirmed with more studies.

\section{ACKNOWLEDGEMENTS}

This study was carried out at the Department of Health Science, Luleå University of Technology as a part of the MemoryLane project, which was supported by the European Union's regional development funds for Sweden. We would like to thank the participants for their cooperation in the study.

\section{REFERENCES}

[1] Sanders, S. (1986) Development of a tool to measure subjective time experience. Nursing Research, 35, 178182. doi:10.1097/00006199-198605000-00016

[2] Sävenstedt, S., Sandman, P.O. and Zingmark, K. (2006) The duality in using information and communication technology in elder care. Journal of Advanced Nursing, 56, 17-25. doi:10.1111/j.1365-2648.2006.03975.x

[3] Thompson, H.J. and Thielke, S.M. (2009) How do health care providers perceive technologies for monitoring older adults? Annual International Conference of the Institute of Electrical and Electronics Engineers (IEEE) Engineering in Medicine and Biology Society, Seattle, 3-6 September 2009, 4315-4318.

[4] van Thiel, G. and van Delden, J. (2001) The principle of respect for autonomy in the care of nursing home residents. Nursing Ethics, 8, 419-431.

[5] Randers, I. and Mattiasson, A.C. (2004) Autonomy and integrity: Upholding older adult patients' dignity. Journal of Advanced Nursing, 45, 63-71. doi:10.1046/j.1365-2648.2003.02861.x 
[6] Boisaubin, E., Chu, A. and Catalano, J. (2007) Perceptions of long-term care, autonomy and dignity, by residents, family and caregivers: The houstone experience. Journal of Medicine and Philosophy, 32, 447-464. doi:10.1080/03605310701626414

[7] Bullock, R. and Hammond, G. (2003) Realistic expectations: The management of severe Alzheimer disease. Alzheimer Disease and Associated Disorders, 17, 80-85. doi:10.1097/00002093-200307003-00004

[8] Steeman, E., Groddies, J., Grypdonck, M., De Bal, N. and Dierckx de Casterlé, B. (2007) Living with dementia from the perspective of older people: Is it a positive story? Aging and Mental Health, 11, 119-130. doi:10.1080/13607860600963364

[9] Steeman, E., De Casterlé, B.D., Godderis, J. and Grypdonck, M. (2006) Living with early-stage dementia: A review of qualitative studies. Journal of Advanced Nursing, 54, 722-738. doi:10.1111/j.1365-2648.2006.03874.x

[10] Niemeijer, A.R., Frederiks, B.J.M., Riphagen, I.I., Legemaate, J., Eefsting, J.A. and Hertogh, C. (2010) Ethical and practical concerns of surveillance technologies in residential care for people with dementia or intellectual disabilities: An overview of the literature. International Psychogeriatrics, 22, 1129-1142. doi:10.1017/S1041610210000037

[11] Powell, J., Gunn, L., Lowe, P., Sheehan, B., Griffiths, F. and Clarke, A. (2010) New networked technologies and carers of people with dementia: An interview study. Ageing and Society, 30, 1073-1088. doi:10.1017/S0144686X1000019X

[12] Nugent, C., Mulvenna, M., Moelaert, F., Bergvall-Kåreborn, B., Meiland, F., Craig, D., Davies, R., Reinersmann, A., Hettinga, M., Andersson, A.L., Dröes, R.M. and Bengtsson, J.E. (2007) Home based assistive technologies for people with mild dementia. Lecture Notes in Computer Science (LNCS), 63-69.

[13] Landau, R., Werner, S., Auslander, G.K., Shoval, N. and Heinik, J. (2010) What do cognitively intact older people think about the use of electronic tracking devices for people with dementia? A preliminary analysis. International Psychogeriatrics, 22, 1301-1309. doi:10.1017/S1041610210001316

[14] Engström, M., Lindqvist, R., Ljunggren, B. and Carlsson, M. (2009) Staff members' perceptions of a ICT support package in dementia care during the process of implementation. Journal of Nursing Management, 17, 781-789. doi:10.1111/j.1365-2834.2009.00985.x

[15] Bowlby, S., Gregory, S. and McKie, L. (1997) Doing home: Patriarchy, caring and space. Women's Studies International Forum, 20, 343-350. doi:10.1016/S0277-5395(97)00018-6

[16] Moore, J. (2000) Placing home in context. Journal of Environmental Psychology, 20, 207-217. doi:10.1006/jevp.2000.0178

[17] Borg, M. (2005) What makes a house a home: The role of material resources in recovery from severe mental illness. American Journal of Psychiatric Rehabilitation, 8, 243256. doi:10.1080/15487760500339394

[18] Oswald, F. and Wahl, H.W. (2005) Dimensions of the meaning of home. In: Rowles, G.D. and Chaudhury, H., Eds., Home and Identity in Late Life: International Perspectives, Springer, New York, 21-45.

[19] Haak, M., Fänge, A., Iwarsson, S., and Dahlin-Ivanoff, S. (2007) Home as a signification of independence and autonomy: Experiences among old Swedish people. Scandinavian Journal of Occupational Therapy, 14, 16-24. doi:10.1080/11038120601024929

[20] Harrefors, C., Axelsson, K. and Sävenstedt, S. (2010) Using assistive technology services at differing levels of care: Healthy older couples' perceptions. Journal of Advanced Nursing, 66, 1523-1532. doi:10.1111/j.1365-2648.2010.05335.x

[21] Topo, P. (1998) Technology in everyday life and care of elderly living at home and suffering from dementia. In: Graafmans, J., Taipale, V. and Charness, N., Eds., Gerontology; A Sustainable Investment in the Future, IOS Press, Amsterdam, 320-323.

[22] Rauhala, M. and Topo, P. (2003) Independent living, technology and ethics. Technology and Disability, 15, 205214.

[23] Magnusson, L. and Hanson, E. (2003) Ethical issues arising from a research, technology and development project to support frail older people and their family carers at home. Health and Social Care in the Community, 11, 431-439. doi:10.1046/j.1365-2524.2003.00446.x

[24] Kikhia, B. (2009) Context-aware life-logging for persons with mild dementia. Annual International Conference of the Institute of Electrical and Electronics Engineers (IEEE), 6183-6186.

[25] Björneby, S., Topo, P. and Holthe, T. (1999) Technology, ethics and dementia. A guidebook on how to apply technology in dementia care. Norwegian Centre for Dementia Research, Oslo.

[26] Osgood, C., Suci, G. and Tannenbaum, P. (1957) The Measurement of Meaning. Board of Trustees of University of Illinios, Urbana.

[27] Tabachnick, B. and Fidell, F. (2001) Using multivariate statistics. 4th Edition, Allyn \& Bacon, Boston.

[28] Harrefors, C., Sävenstedt, S., Lundquist, A., Lundquist, B. and Axelsson, K. (2011) Professional caregivers' perceptions on how persons with mild dementia might experience the usage of a digital photo diary. The Open Nursing Journal, 6, 20-29. doi:10.2174/1874434601206010020

[29] Elo, S. and Kyngäs, H. (2008) The qualitative content analysis process. Journal of Advanced Nursing, 62, $107-$ 115. doi:10.1111/j.1365-2648.2007.04569.x

[30] Graneheim, U.H. and Lundman, B. (2004) Qualitative content analysis in nursing research: Concepts, procedures and measures to achieve trustworthiness. Nurse Education Today, 24, 105-112. doi:10.1016/j.nedt.2003.10.001

[31] Edlund, M. (2002) The human dignity: A basic caring concept, (Swedish). Ph.D. Thesis, Åbo Academi University, Åbo.

[32] Nordenfelt, L. (2004) The varieties of dignity. Health Care Analysis, 12, 69-81. doi:10.1023/B:HCAN.0000041183.78435.4b 
[33] Slettebø, A., Caspari, S., Lohne, V., Aasgaard., T. and Nåden., D. (2009) Dignity in the life of people with head injuries. Journal of Advanced Nursing, 65, 2426-2433. doi:10.1111/j.1365-2648.2009.05110.x

[34] Cooley, C.H. (1964) Human nature and the social order. Schocken, New York.

[35] Pohlmann, C. (2006) Who shapes the self of independents and interdependents? Explicit and implicit measures of the self's relatedness to family, friends and partner. European Journal of Personality, 20, 525-547. doi:10.1002/per.599

[36] Westius, A., Andersson, L. and Kallenberg, K. (2009) View of life in persons with dementia. Dementia, 8, 481499. doi:10.1177/1471301209350287

[37] Westius, A., Kallenberg, K. and Norberg, A. (2010) Views of life and sense of identity in people with Alzheimer's disease. Ageing and Society, 30, 1257-1278. doi:10.1017/S0144686X10000309

[38] Kitwood, T. (1998) Toward a theory of dementia care: Ethics and interaction. The Journal of Clinical Ethics, 9, 23-34.
[39] Flanagan, C. (2003) Trust, identity and civic hope. Applied Developmental Science, 7, 165-171. doi:10.1207/S1532480XADS0703 7

[40] Andersson, M. (1994) Integrity as a concept and as a principle in health care ethics, (Swedish). Ph.D. Thesis, Åbo Academi University, Åbo.

[41] Cahill, S., Macijauskiene, J., Nygård, A.M., Faulkner, J.P. and Hagen, I. (2007) Technology in dementia care. Technology and Disability, 19, 55-60.

[42] Cahill, S., Begley, E., Faulkner, J. and Hagen, I. (2007) "It gives me a sense of independence"-Findings from Ireland on the use and usefulness of assistive technology for people with dementia. Technology and Disability, 19, 133-142.

[43] Fung, A.W.T., Lam, L.C.W. and Lui, V.W.C. (2010) Could hypothetical scenarios enhance understanding on decision for life-sustaining treatment in non-demented Chinese older persons? Aging and Mental Health, 14, 994999. doi:10.1080/13607863.2010.501065

[44] Patton, M.Q. (2002) Qualitative evaluation and research methods. 3rd Edition, Sage, Newsbury Park. 